\title{
A Holistic Approach to the Mechanisms of Music Engagement
}

\author{
ANNA IBÁÑEZ CANTÍ, Universitat Oberta de Catalunya (UOC)
}

\begin{abstract}
Meaning is encoded in the production and decoded by the audience during the consumption, which is why it is a process of constant feedback. Each person experiences meaningful connotations in relation to their favourite music, hence music occupies a particular position in each one's life and within the cultural life of particular individuals and groups.

Music meaning and emotion has been studied by David Carr (2004), who wonders if emotion is intrinsic in music, or if it is a symbolic representation - or rather if emotions are projected from the listener onto the music. Like Akio Morita (the co-founder of Sony, and the person behind Sony Walkman), Jean Baudrillard argues that meaning does not reside in an object but in how that object is used (Du Gay et al. 1997, 90). Is there a relation between what music means to an individual and his/her preference for a particular genre?

The methodological approach is mainly qualitative. I have analysed 215 responses to an online questionnaire, and followed this with an analysis of 8 semi-structured in-depth interviews. I seek to comprehend the space that music occupies in the net of relationships that constitute culture, and to discover the mechanisms of taste configuration in relation to music-meaning within a holistic approach, encompassing the circuit of culture as a theoretical framework.
\end{abstract}

\section{KEYWORDS}

Circuit of Culture; Music Preferences; Audiences; Music Meaning; Music Engagement 


\section{Introduction}

There is no such thing as free individual choice. All of our individual choices are influenced either by demographic or socioeconomic forces. Choices are influenced by the culture we live in, the values of our society, our age, our gender, our place of residence, our parents and friends, our class and our status. Hence, meaning-making might be a part of the process that results in such choices made. This is the main focus of this essay: to understand the ways and the components by which we engage with the music we choose to listen to.

Music preferences encompass so many different aspects of human existence and, as happens with many other subjects, technology plays a significant role when music becomes the main discourse of sociological research, since music has specially developed hand-in-hand with technological evolution. To give a broad picture of how we got where we are now, it is essential to be aware that before the nineteenth century, the audience could only consume music when it was played live, and repeated consumption was possible only with repeated performances (Ordanine \& Parasuraman 2012). The disembodiment of music, understood as music leaving the human body as a container, started slowly with the culmination of musical notation by Guido de Arezzo at the beginning of the eleventh century. From that moment, music has evolved at a breakneck speed if compared with the evolution music had until this moment of inflexion (Howard 2005). From that instant, occidental music separated from the music of the rest of the world. With the industrialization during the nineteenth century, a massive technological transformation occurred and together with the evolution of the piano and the new bourgeoisie class, new business arose in the commercialization of music: music scores. At the beginning of the twentieth century the phonograph and the radio were invented and consequently the mass commercialization of music began by the trade of music recordings. In that moment a need emerged for classifying audiences, and therefore music was divided into 7 different categories (Howard 2005). Nowadays these categories have evolved to numerous genres and subgenres that, arguably, on top of offering variety, also bring the audience into a state of confusion.

One aspect of where technology becomes very relevant when thinking about music preferences and music meaning-making is how it determined the evolution of sound systems. James Hellbrun (1993), in his paper entitled Innovation in art, innovation in technology, and the future of the high arts, reflects how the sophistication and innovation in home stereo sound system can be one of the causes of the lack of attendance to symphonic concerts, hence it might play a role in influencing music preferences. The context and the sharing experience with others seems to play a less important role if, in this case, classical music is compared with modern concerts. According to my findings only $16 \%$ of the respondents never listen to classical music while as much as $50 \%$ do not attend classical music concerts. Hence, there are $34 \%$ of the respondents who listen to classical music but do not attend concerts, and $25 \%$ only attend classical music concerts once a year. I can relate this to Hellbrun's findings, who states: 'You can sit at home with your feet up, as the advertising copywriter might put it, and hear a concert of your own choice in greater comfort and at much less expense of time and money than would be required to hear it live. No doubt, live performance is better [unless the recorded artists are notably superior to those in the concert hall], but is it enough better to justify the expense and bother? Evidently, a great many music lovers think not' (Helibrun 1993, 90-91). Choosing to listen to music at home or attending a concert might also have modified the relationship that individuals have with music, affecting directly the meaning music has for each one of these listeners, therefore, becoming a component of engagement with music.

Moreover, the internet has made possible to digitalize music and to allow it to be stored, manipulated and transported without an appreciable loss of fidelity, in a practically total 
disembodiment of the music from the musician (Howard 2005). Mentioning disembodiment implies to think about embodiment, since music is not something floating around. Music needs a body, whatever it is a mp3 player, a $\mathrm{CD}$, a server, and here is where technology, and how music is embodied, affect the way it is produced, the way it is consumed, the way it is reproduced, how it is represented, how it is regulated and at thus, how it affects our identity. Consequently, the body, where music incarnates, might have a direct relationship with the listener process of meaningmaking because changing of the context might result in a change of the meaning. To sum up, components of engagement have to be found in a mix of variables and the relationship between them in a transdisciplinary study, taking into account musicology, sociology and neuroscience.

\section{State of the Art}

Meanings are encoded in the production and decoded by audiences during the consumption, which is why it is a process of constant feedback. Each person experiences meaningful connotations in relation to their favourite music, hence music occupies a position in each one's life and within the cultural life of particular individuals and groups. Music consumption can be approached from different angles depending on the question you want to answer, but there are two perspectives that underscore this essay: the habits of consumption (i.e. how people consume music) and what music means to each audience (i.e. why people consume music). There are two main analytical frameworks one can use to answer these questions: on the one hand a neuroscientific approach and on the other hand a sociological one. In the middle of both analytical frameworks, which is not the centre, David Carr (2004) settles what could be presented as an analytical framework when he wonders whether emotion is intrinsic in music, if it is a symbolic representation or if emotions are projected from the listener into the music. It is in this middle area where I have found the inspiration for writing this essay: a vast area and a fertile field for innovation.

In what technology is concerned, both digitalization and re-embodiment of music is intrinsically tied to music sharing technology, which has been studied in multidisciplinary research, for example in Sumanth Gopinath and Jason Stanyek's edited collection: The Oxford Handbook of Mobile Music Studies (2013). Moreover, there is an earlier collection of papers published in 2006: Consuming Music Together: Social and Collaborative Aspects of Music Consumption Technologies (O'Hara \& Brown 2006), that approaches most of the aspects that arise from the use of applications like iTunes in an online social networked environment, as well as the changes that have happened between individuals and the experience of listening to music. As these works have argued, listening to music has become an individual action and not something to be only shared with both the audience and the musician. Nonetheless, one's music choices can be shared online in applications like iTunes or Spotify, music becomes a public identification or image of each individual or group (O'Hara \& Brown 2006). Nowadays, the social importance of music and identity is highlighted by the collaborative and sharing culture of this day and age, although not everybody likes sharing music, because for some people music taste is a totally private matter.

Dulce (19): 'I don't really share music. I don't like the idea, it is something kind of private, I prefer it to be private. "That girl is listening to this right now"...no...I don't really find it that necessary. It really is something private to me, a disconnection moment, it is not necessary that everyone know what you are listening at that moment...'

Julia (20): 'I don't share music on Facebook, what I keep I keep it for me, you know?'

Based on the results of the questionnaire and the in-depth interviews, respondents do not have much interest in sharing their music preferences and actually $39 \%$ of them said they never share music 
through social networks or through music sharing technologies. Moreover, only $28 \%$ of the respondents frequently share music through these channels. It has to be taken into account that most of the respondents are from urban environments, finished secondary studies and are internet users (this online questionnaire was sent by email and social networks, hence to be able to respond to it, the individual had to be an internet user - i.e. not sharing music seems not to be, or at least, seems not only to be linked to the lack of tools such as internet access or the lack of knowledge.

Many authors have studied how technology not only changes the ways in which music is consumed (stored, performed, transported) but also the habit in a bigger frame (or habitus in the words of Bourdieu), as McLuhan said: 'We shape our tools and afterwards our tools shape us' (Coupland 2010). From this statement it can be inferred that the consumer's habits have changed strongly since the mass use of digital music. Hence, media technologies change culture which changes with society, who creates meaning at the interface between culture and technology. I believe that McLuhan would probably agree that the 'know-how' of each of these new media technologies is where culture production is sustained, produced and reproduced, and therefore it is often called social technology (Du Gay et al. 1997, 23). I opine that it is in this broader analysis of culture where the limits of both technological and sociological deterministic views, often found in recent studies, can undergo more exploration.

This framework is specially challenging for research of music preferences. Many studies based on neuroscience agree that we prefer what makes us feel more comfortable, but not too comfortable, so it does not become boring and too predictable. A research group headed by Eckart Altenmüller found out that familiarity (whether with a music style or with personal factors) had a strong response related to reward dependence, which could be linked to a sensation or emotional realising. As Thompson $(2006,218)$ writes: 'Collative variables-informational properties of the stimulus such as its degree of novaly/familiarity (Norht \& Hargreaves 1997, 87) are the most important in determining affective response'. Hence, there is a general hope for simplicity. Vuust \& Kringelbach (2010) also state that the listener might feel released when anticipation and expectancy is fulfilled. These emotions are tied to the reward system of the brain, which is somehow related to survival. Studies based on neuroscience highlight the neurotransmitter dopamine which is linked to reinforcement, learning and reward seeking behaviour as it is the case of fulfilled expectancy in music (Vuust 2010, 177). Musical anticipation/prediction is a mechanism where musical patterns might establish, confirm, delay or violate, and the simplicity or complexity of these patterns will depend on the knowledge of the listener.

Thus, this musical anticipation is shaped in the brain structures by both culture and personal listening history and musical training, (Vuust et al. 2005 - cited in Vuust 2010, 171). It is in this point where both approaches, namely: neuroscience and sociology, meet. This learnt experience that constitutes -in this concrete case - our range of music knowledge is what also Gregory Bateson $(1979,15)$ calls transference, meaning that the shape of the today's experience is determined by the past learning, and I believe it is at the same time related to the survival system. So, music knowledge (cultural, personal listening history and musical training) is transferred from the past. The concept of transference is appropriate to explain how anticipation works and how presupposition is constructed, but it is a limiting concept since it does not emphasize enough about how this past is constructed and how the actual process of transference works. For a better understanding and a large-scale explanation there is the concept of habitus from Bourdieu, which includes more than a past experience: it includes the social context, the culture and the society where the subject develops. Habitus is not limited to a mere relationship between A and B; it embraces a lot more, its history, its instruments of social construction, somehow a meta-structure of the world. 
Other theories have been built to support or oppose Bourdieu's theoretical framework. Guerzoni \& Nuccio $(2013,8)$ find in Bourdieu's class distinction (based on the cultural consumption) an 'ideology of natural taste'. According to this, the innate predisposition to appreciate art is only found in a limited group of people. I would like to point out that if music appreciation has something to do with anticipation (as shown above) and anticipation is based on the individual variety of known patterns and expectations, then we could classify society between different patterns of anticipation and maybe then understand the components that would take part in scaling this repertoire of patterns and so divide society upon its cultural consumption and not the other way around as Bourdieu does.

I find Bourdieu, in this day and age, limiting in some aspects, since he takes social class as a determinant in culture consumption, being sometimes too objective while representing social class and getting very static results. This is probably because of the quantitative approach and highly structured questionnaires employed without reaching the insights of the population. As du Gay writes: 'although Bourdieu indicates the importance of consumption to the production and reproduction of class divisions, he is unable to explain the ways in which consumer practices may crosscut given social divisions creating new social identities and differences in the process' (du Gay et al. 1999, 98-99). Guerzoni \& Nuccio (2013) attribute this gap in Bourdieu theoretical framework to the evolution of society itself and to the postmodernist paradigm characterised by the rise of individualism, the value of authenticity and the self-determination (Taylor, 1991). Zygmunt Bauman (1988) synthetizes this by saying that "cultural consumption and lifestyle are losing their grounding in social stratification and are becoming a matter of self-realization, which cuts across classes and choices'. This is the reason why I focus on individuals and not on communities, but I do it in the context of a holistic approach which takes into account elements like consumption, representation, regulation and production, which in fact are intrinsic in social groups.

\section{Methodology}

I have chosen the Grounded Theory (GT) approach since I did not have a prior hypothesis or predefined theoretical framework. I chose GT because it is a method where the theory is grounded in data; it is not a descriptive method, hence is very useful for behavioural research, as it is the case here. Through this method, which deals with conceptual level data, I have taken the incidents as units of analysis instead of the individuals. The aim is to conceptualize what is going on by using empirical research. In addition, the grounded theory is based on symbolic interactionism, whether referring to its classical theory or the revised one by Strauss and Corbin (1990). The revised GT (which I have used in this paper) maintains the cyclic connections between the research question, the analytical framework and the theoretical framework; therefore it is also based in data, but with a more systematic approach through coding deriving to a more conceptual description.

In this study, I carried out eight in-depth interviews with two men and six women. The interviewees were between 19 and 34 years old, since this group, according to the results of the statistics about cultural consumption habits in Spain by the Spanish Ministry of Culture (Ministerio de Cultura 2010-2011), belongs to a range of age where music use is more 'active': they are the ones who mostly listen to music and also attend more concerts in general.

In addition, I designed an anonymous Google Drive questionnaire. It was sent by email to 70 of my contacts and also to all the students from the two virtual mentor classroom from the Universitat Oberta de Catalunya (UOC) which had around 400 students. I also shared the survey link on my social networks and asked people to respond to the questionnaire and share it. Even though this may not be a representative sample, I got enough answers (213) to consider it indicative of music-related 
trends. However, it is important to remember that respondents' profiles may not be embracing a wide range of population types since the method I used to spread the questionnaire has been using my own social circles: most of the individuals have a degree or postgraduate studies (bachelor, master or $\mathrm{PhD}$ ) and a 53\% of the respondents are studying at the university: $19 \%$ on a bachelor's programme, and $17 \%$ on a master's degree programme (and additionally there is $17 \%$ of respondents who answered 'others' about education, which could indicate a specialization). $20 \%$ of those who did not finish university education could be a big part of the young ones who did not finish their degree yet (13\% of respondents are younger than 24 years old). Most of the respondents are in the range of 25-44 year old (Fig.1) which is limiting when considering a quantitative approach analysis, but the most substantial part of this questionnaire is not in the quantitative responses about music habits (which answers can be found in the survey that the Spanish Government carries out every two years) but in the qualitative responses about their experiences of music engagement. 213 responses are not enough to take the findings conclusively, but I opine that it sets the basis for a wider study.

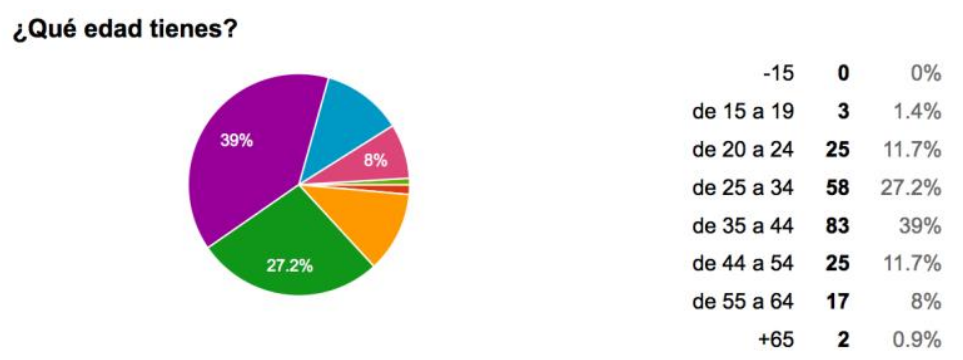

Figure 1: Age range - results from the online questionnaire

From the literature review I have identified general ideas that have a significant relation to the categories I was using in parallel during the analysis of in-depth interviews (which where conducted prior to the design of the online questionnaire). Initially, I conducted open coding that led to categories, which later became families of codes. I found that 'categories' was a very limiting concept and employing a family of codes allowed for more flexibility and broadness when putting together my ideas. Furthermore, interviews have an implicit conceptualization of categories, due to the whole verbal interaction. After organizing the categories in 'families' I aggregated the codes emerging from the data. This resulted in a relation between data and the specific theoretical framework used in one of the books I was reading during this process: Doing Cultural Studies: The story of the Sony Walkman by Paul Du Gay et al. (1997) which had a big impact on my thinking and I decided to use it as a theoretical framework. This study identifies five major cultural processes: Reproduction, Identity, Production, Consumption and Regulation, completing what it is called the circuit of culture 'through which any analysis of a cultural text or artifact must pass if it is to be adequately studied using, in this analysis, the Walkman as a case-study' (1997, 3). Thus, in the intersection between this book and the empiric data I gathered, I have found the possibility to explain music meaning through the element 'identity' (in relation with the other 4 elements) by finding a middle point between theory and practice.

\section{Results and discussion}

Music itself does not have an identity, but identity is the result of the meaning that individuals and audiences project or give to music. This projection is defined by the subject's values, which are learnt in a social context, which in turn implies a net of relationships, experiences, opinions, etc. 
Identity, according to Bourdieu, is explained as almost an object. The 'self' as any other thing, occupies a position in a physical space and therefore in a social space. To pertain, as an individual, to a social space has implicit inclusion and exclusion. Consequently, identity can be explained both from where the individual pertains and where do not pertain. During my in depth interviews, those who showed more engagement with one type of music genre were the ones that also showed more repulsion to other music genres.

Feliciano (24): 'My taste is contained within the borders of the United States. Whatever that is not from the United States, I don't like it. I am very American, very black. Jazz, soul and hiphop, basically hip-hop. I don't listen anything else. (...) Somehow it is a way to value more the music I like. I am not the typical person who listens to everything and I like everything, because that means that you don't really value the musicians that are, in your opinion, good.'

Akio Morita (the co-founder of Sony and considered by many as the inventor of Sony Walkman) as well as Jean Baudrillard argued that meaning does not reside in an object but in how that object is used (du Gay 1997, 90). So, the way an object is used has a lot to do with the meaning the user gives to this object. The parameters of meaning are not intrinsic in the music but related to anticipation, presupposition and associations I had mentioned earlier. Therefore, in this essay I refer to the meaning and engagement individuals have with music rather than if a specific genre produces a particular effect.

What does music really mean to people? To get the answer I formulated a question in the online questionnaire to know which words could better relate to respondent's favourite music. To give a more visual result I configured a word cloud with the words given by the respondents. In order to be able to make a reliable word cloud, I translated the words that were originally in Spanish and also I unified the words that had same meaning but were written differently, for example: 'relax, relaxation, to relax' became 'relaxation', or 'inspiration, inspiring, inspires me' became 'inspiration', etc. Figure 2 shows the result of 186 answers as a word cloud made through Hiper Research software by using the first 47 words, which means that the least repeated word had 3 occurrences.

Word Count in Cloud View for source files:

cloud186.rtf

emotional life activaton feeling comen inspiring rhythm

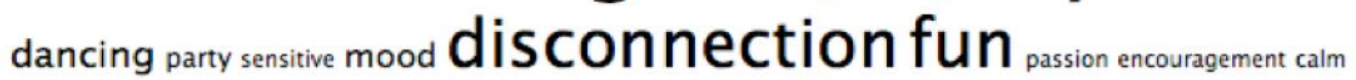
lively Cheerful tranquillity goodvibes happiness culture peace evocative

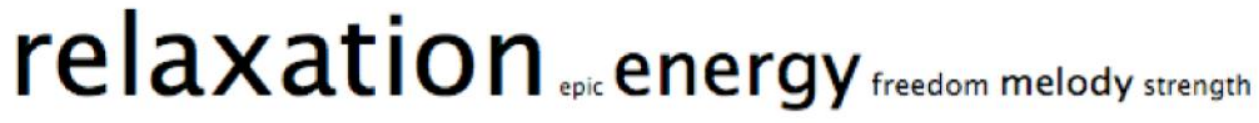

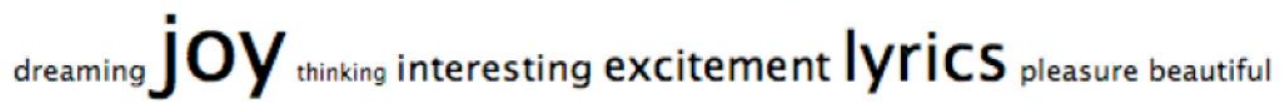
openness deep imagination memories motivation serenity $\mathrm{C}$ company

Figure 2: Association word cloud 
Figure 3 shows the ten words that occurred most frequently.

\begin{tabular}{|l|l|}
\hline Word & Count \\
\hline relaxation & 25 \\
\hline emotion & 20 \\
\hline joy & 20 \\
\hline rhythm & 19 \\
\hline feeling & 19 \\
\hline energy & 16 \\
\hline disconnection & 14 \\
\hline lyrics & 14 \\
\hline fun & 14 \\
\hline cheerful & 12 \\
\hline
\end{tabular}

Figure 3: Top 10 repeated words

To have a more concrete panoramic view of what kind of meaning are audiences looking for when they configure their music taste, I grouped the words provided by the first 186 respondents into families. The word classification has been completely intuitive so it is important to remember that there is a strong subjective component limiting the results. Words like, for example, 'youth' could be classified as a present, positive feeling if written by a 20 -year-old respondent, but it could be linked to nostalgia of the past if that word was written by a much older person. The goal of this semantic classification is to have a first approximation to different type of meanings. Nonetheless, in a further investigation it would be interesting to study if the respondents combined different type of words or, in contrast, their words pertain to the same semantic group.

To sum up, I have found that music fulfils five aspects of the human experience. Music moves emotions, experiencing a kind of ecstasy, which could result from either power and joy or nostalgia. Music allows listeners to disconnect from their daily life and their daily problems, being therapeutic and bring comfort, distraction and, therefore, disconnection. Also, music brings energy and happiness through rhythm that helps audiences to cheer up and become 'activated'. Moreover, music inspires: it goes deeper into listener's souls, creating an intimate, even mystic, experience and brings listeners to expand and heal and open to the world and to themselves. Lastly, there is a descriptive list of words that describe elements of music (melody, lyrics, message) but they also can be analysed as more 'abstract' elements: message, mental, culture etc. Popular music, and probably also classical music or jazz or any other kind of other music, is also enjoyed from a rational point of view. So, different types of music may adapt better to one or more audiences' cultural needs. Mostly, music moves feelings, from nostalgia to absolute happiness and communicates with ourselves (inner world) and with the world itself. Music takes an important role on the cultural construction of subjectivity.

Both from neurological studies and from sociological studies, it is shown that there is a strong connection between music and emotion. Moreover, a particular music can also link to memories, personal experiences, to people, to places, etc. (Vuust $(2010,169)$ calls it extramusical association). Therefore, while experiencing music is a subjective experience, the subject experiences it through external inputs. Thus through my data I could observe that 'music is a material that actors use to elaborate, to fill out and fill in, themselves and to others, modes of aesthetic agency and, with it, subjective stances and identities' (De Nora, 2006, 147) and, following DeNora, this is what I define as cultural construction of subjectivity in this paper. 


\begin{tabular}{|c|c|c|c|c|c|c|c|c|c|}
\hline joy ....... & & relaxation & 25 & rhythm. & 19 & lyrics. & & feeling... & 19 \\
\hline emotion & 20 & disconnection & 15 & energy & 16 & interesting & & Jinspiring & 10 \\
\hline feeling. & 19 & peace & 9 & fun & 14 & melody..... & 7 & company. & 6 \\
\hline mood & 8 & tharmony & 8 & cheerful & 12 & cuiture. & 6 & evocative & 6 \\
\hline emotional & 6 & tranguillity & $6]$ & excitement & 8 & thinking & 3 & beautiful & 3 \\
\hline memories & 6 & dreaming & .5 & dancing & 7 & voice & 2 & imagination & 3 \\
\hline encourageme & 3 & pleasure & 5 & happiness & 7 & sound & 2 & openness & 3 \\
\hline sensitive & 3 & serenity & 5 & lively & 75 & different & 2 & reflection & 2 \\
\hline deep & 3 & content & 3 & freedom & 5 & commercial & 2 & meaningful & 2 \\
\hline passion. & 3 & calm & 3 & vibes & 4 & quality.............. & 2 & atmosphere & 1 \\
\hline soul & 2 & evasion & 2 & party & 4 & driving. & 2 & divinity & 1 \\
\hline power & 2 & comforting. & 2 & strength & 4 & stress & 2 & reflective & 1 \\
\hline force & 2 & escape & 2 & life & 4 & classical & 2 & penetrating & \\
\hline forceful & 2 & comfort & if & activation & 3 & riffs & i) & sensory & 1 \\
\hline courage & 2 & distraction & 1 & epic & 3 & business & i. & subtlety & 1 \\
\hline real & 2 & welfare & 1 & 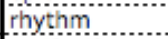 & 3 & innovation & . & expansive & 1 \\
\hline melancholy. & 2 & fresh & i] & motivation & 3 & acoustic & if & close & 1 \\
\hline poetry & 2 & antistress & it & humourous & 3 & square & it & breadth & 1 \\
\hline expression & 2 & weiliness & i] & catchy & 2 & mental & i) & heartfelt & 1 \\
\hline fulfilment & 2 & relax & 1 & movement & 2 & visual & i) & pure................. & 1 \\
\hline powerful & 2 & relief & 1 & entertainment & 2 & symphonic & it & depth & 1 \\
\hline intensity & 2 & chili & 1 & positive & 2 & miscellaneous & 1 & genuine & 1 \\
\hline fallinginove & i) & warm. & 1 & friendly. & 2 & variety & 1 & communion & 1 \\
\hline sublime & i) & & 100 & vitality & 2 & concentration & 1) & elevation & 1 \\
\hline committed & 11 & & & swing & 2 & vocal & if & vulnerability & 1 \\
\hline pride & 11 & & & friendship & 2 & $70 \mathrm{~s}$ & 1 & inflection & 1 \\
\hline elegant & 11 & & & dynamic & 2 & singing...... & 1 & Mystery.... & 1 \\
\hline intense & 11 & & & stimulus & 1 & intelligent & it & lendearing & $\dddot{1}$ \\
\hline everything & 11 & & & high & 1 & rebellion & if & clearity & 1 \\
\hline flying........... & . & & & groove.... & 1 & repetition & 1 & healing.. & 1 \\
\hline nostalgia. & n. & & & euphoria & 1 & composition & 1 & blue & 1 \\
\hline sensual & 11 & & & optimism & 1 & guitars & it & intriguing & 1 \\
\hline nostalgic & 11 & & & stimulating. & 1 & rich & if & silence.... & 1 \\
\hline reassurance & 1. & & & entertaining & if & time & 1 & message & 1 \\
\hline vastness & 11 & & & goodhumour & it & worked & .1) & drawn & 1 \\
\hline adrenaline & 11 & & & sexy & 1 & usefül & i) & intimacy & 1 \\
\hline discover & 11 & & & youth & $\ldots i$ & understandab & if & transformation & 1 \\
\hline feelings & 1 & & & & 154 & personality & 1 & independent & 1 \\
\hline sentimental & ii & & & & & select & i) & personal & 1 \\
\hline strong & 1 & & & & & fine & it & independence & 1 \\
\hline enrichment & il & & & & & Easy & 1 & self & 1 \\
\hline vibrating & il & & & & & travel & 1. & & 88 \\
\hline magnificent & 11 & & & & & style. & 1 & & \\
\hline love & 1 & & & & & & 833 & & \\
\hline \multirow[t]{2}{*}{ sad. } & $\cdots_{11}$ & & & & & & & i & \\
\hline & 138 & & & & & & & ! & \\
\hline
\end{tabular}

Figure 4: Families of categories

All of my interviewees mentioned several times how music helped them cheer up or, on the contrary, brought them to a state of relaxation. This corresponds very well with the responses I received through my questionnaire. Music and emotion are strongly present in listeners' lives. According to my data, the listeners even organize some of their music according to their emotional states. The listeners' playlists, either in Spotify or in iTunes, have names like party or relax and, especially those who like commercial music, do not organise the playlists by artist or band names. Subsequently, I have found a difference in engagement between those who said they liked commercial music and those who said they did not and instead differentiated themselves as 'having better taste'. Three of the interviewees, and especially the two hip-hop fans in the study said to listen to specific artists, but one respondent who listened to commercial music said he chose what was 'on' at the moment and 'detached' from what they have been listening once a new song comes on, keeping the olds ones in a kind of memory box (or in an abandoned nostalgic playlist) which the respondent would only listen to in order to bring up old memories.

Another aspect that has a major importance when analysing consumption data is the context. Music itself is just a part of the listening experience. The place, the gestures of the performance, the implication of the audience, the light, the news, the time, the weather, etc. are all part of the experience because all these factors can influence the subjective experience of each listener. To think about the context and art prompts me to recall the insight of Walter Benjamin. In his essay The Work of Art in the Age of Mechanical Reproduction (1936), Benjamin stated that mechanically 
reproduced art (or electronically reproduced, if we think in actual terms) would change the relationship between mass audience and art itself. He stated that mass audience look for distraction while art looks for the observer's introspection ('recolliment'). Benjamin discourse revolves around the idea of 'de-contextualization of art' which reaffirms the importance of the context. Benjamin writes about how the 'aura' of an art piece is lost when it is taken out of context, and nowadays we can consider, for example, listening to a Bach cello suite through an mp3 file at home and listening to it in the XVII century in a German salon - two completely different contexts, not only in the place and in the historic time, but in the whole consciousness and perception of the reality that pertains to the era.

Therefore, context influences also how audiences construct meanings. As I have found after analysing the results of both in-depth interviews and the questionnaire, the context is what can affect how much individuals can identify with each type of music. Results from the online questionnaire indicate that national (Spanish and Catalan) pop/rock, the works of national and international songwriters, blues/soul, Catalan rumba, reggae, world music and classical music would be close to individuals if the context were the appropriate. Flamenco, Latin music, salsa, hard rock, metal, punk and hip-hop is less likely to depend on the context but rather on individual preferences (either you like it or you don't).

One aspect that has a lot to do with identity is authenticity. According to Charles Taylor, authenticity revolts against convention, in that 'authenticity is itself an idea of freedom; it involves my finding the design of my life myself, against the demands of external conformity' $(1991,68)$. This very much resembles Bauman's idea of self-determination explained earlier in this paper. Thus being against the demands of external conformity could also mean showing dislike for mass commercialized music. What I have found unexpected in the study are the results of the type of music which most of people in the study have listened to (generally), or listened to when going out to party. It seems there is not a great deal of engagement with such music, since $40 \%$ of the respondents did not feel identified at all with this type of music, even though it is mass commercialized. One of the characteristic of commercial music is actually how predictable it is (it can become boring by being too predictable), so I wonder if the variety of anticipation spectrum that each of us have has something to do with music engagement.

Being authentic also means differentiating oneself from others. Feliciano does not only differentiate himself from the rest of the population by his chosen music, but for him the 'real' hip-hop also helps him differentiate from those who like the 'real' hip-hop but do not appreciate it as much as he does. In his own words:

'What I don't like about live hip-hop concerts is the atmosphere, I suppose it is like everything else, if you have a big respect for something, if there is somebody around who doesn't feel the same respect as you do, it hurts, do you know what I mean?... Some people go to the concert and smoke weed and look at people around, you know? Hip-hop attracts bad people, there are people who like this music because it makes them more urban, and I am more...'

Feliciano sees himself as more of a music lover, and definitely he identifies with this music, unlike many of other hip-hop listeners who, as he believes, do not appreciate the music as much as he does. There is a kind of cognitive dissonance with his self-image and the image he may give to others who associate hip-hop to this urban 'gangster' profile Feliciano describes. Although hip-hop consumers are a very closed or rather a particularly focused culture and so I have wondered if that would make hip-hop fans be perceived as people with strong personalities - as apparently they 
seem to perceive themselves. The results indicates that respondents feel mostly indifferent (54\%) about this, $25 \%$ do not agree at all, 12\% agree a little bit and only $9 \%$ agree quite a lot or a lot.

Each one of us carries around their own way of making sense of things and this includes music: our own values, our own concept of what are and are not right relationships (Small 2001, 346) but these personal values, according to Bourdieu (1997) are socially constructed as individuals are socialized bodies. In addition, we value people who share our values, and these concepts and values are both socially constructed through the shared perceptions of the various social groups to which one belongs and also the individual itself, its own experience and temperament (Small 2001, 347). That is where many of the studies in the field find their limitations: in dividing music genres and audiences without looking if actually the music itself (melody, rhythm, harmony) has something to do with the taste and engagement, or if choice is more related to pertaining to a social group that they feel identified with.

According to my results, $57 \%$ of the respondents have not changed their music preferences since they were teenagers, so it might indicate that in a big part of the population, adult music preferences foster in the early period of our lives. In further research, it would be interesting to examine this aspect in a deeper way in order to understand the role of education during childhood and puberty and its relationship with the mechanisms that configure music taste.

Thus, through the circuit of culture mentioned earlier it is possible to explain how and why cultural practices and institutions have to come to play such an important role in our lives, and using the circuit of culture becomes very useful to identify music as a cultural practice and thus as a cultural artifact. Therefore is possible to understand the mechanisms of meaning-making while a wider consideration for the individual experience rather than analysing audiences as a whole and relating them to social groups. Studies show that music genres are related to social differentiation because each genre shares some of this meaning with the social groups, which in turn share aspects of their identity. Continuing this research I would like to answer what comes first: the meaning or the social group. Do I become a punk because I like punk? Or I like punk because my friends are punks?

Audiences and its individuals project meaning into the music in order to fulfil their needs, emotional, mental or physical and therefore music is produced to satisfy music taste. Production and consumption are reciprocally united and consumption habits are fostered from childhood. Guerzoni and Nuccio (2012) point out in their conclusion that past consumption has a big influence on future consuming. Moreover, results have shown that audiences project meaning onto their favourite music, and reciprocally music itself produces effects on the listener's needs (of 'soul' fulfilment, intellectual fulfilment or optimisation of their daily tasks etc.). Hence, audiences develop consumption habits through their own socialization and here is where context has, again, a special importance. Music choice is influenced by time and a space and therefore music consumption will not only depend on each individual preference but on its accordance with context.

Identity itself cannot be explained outside of its own context, which involves the other four elements of the circuit of culture. Production is strongly tied to marketing, since it needs a channel to pass its products, which is why production implies awareness of different cultures and lifestyles to be able to target its public. Du Gay (1997) defines this process as 'production of consumption', implying that consumption influences production reciprocally. In addition, the ways in which music is represented seem to have a major impact on the other elements in the circuit. Music preferences may be developed slowly from childhood, and so music should be introduced at school and in the society through media and government. Regulation plays a big role too, as it becomes more present when it takes a social dimension. Its genre is associated to a lifestyle or person type, which impacts the construction of identity. 


\section{Conclusion}

In this essay I have taken the circuit of culture as a theoretical framework in order to have a holistic approach to the scope of music meaning-making (which I believe is tied to music engagement). I have focused on the element of identity as an outcome of the interaction with the other elements. In addition, I have underlined the net of relationships that constitute the circuit of culture through the concept of habitus from Bourdieu, which I believe is where the mechanism of meaning construction begins to foster.

As a general conclusion, I state that meaning has a lot to do with how music is used and there are three more detailed explanations for this: (1) music influences listeners' emotional states that can go from euphoria and excitement to nostalgia and self-reflexion, becoming sometimes a spiritual experience, (2) music helps with some everyday tasks more pleasurable: for example, accompanies travelling (whether by car or by foot with an mp3 player), or helps concentrate while studying or while doing work at home etc., (3) music enriches the intellectual needs of people who study how music works or analyse it.

The concrete types of music that may result in these 'uses' will depend in the spectrum of anticipation for each of us, on the memories anchored in the music, on the spatial context of where we are, on the education we have received, and on the ways in which music is represented in a social context. In my further research, I would like to work on these initial, pilot results and to measure the levels of engagement that have each of the aspects mentioned in this essay, investigating how the technological developments have shaped the present reality.

\section{References}

Ariño Villarroya, A. (2008) 'Música, Democratización y Omnivoridad', Política y Sociedad, 44(3), 131-150.

Bateson, G. (1979) Mind and Nature: A Necessary Unit, New York: E.P Duton.

Bourdieu, P. (1997) Pascalian Meditations, Paris: Editions du Seuil.

Carr, D. (2004) 'Music, Meaning, and Emotion', The Journal of Aesthetics and Art Criticism, 62(3), 225-234.

Coupland, D. (2010) Extraordinary Canadians: Marshall McLuhan, Toronto: Penguin Canada.

Coupland, D. (2010) Marshall McLuhan: You Know Nothing of My Work!, New York: Atlas \& Co.

Cross, I. (2008) 'Musicality and the Human Capacity for Culture', Musicae Scientiae, 12(1 Suppl), 147-167.

DeNora, T. (2006) 'Music and Self-Identity' in A. Bennett, B. Shank \& J. Toynbee (eds), The Popular Studies Music Reader, New York: Routledge, pp-141-147. 
Du Gay, P., Hall, S., Janes, L. and Mackay, H. and Negus, K. (1997) Doing Cultural Studies: The story of the Sony Walkman, Milton Keynes: Open University; Thousand Oaks, CA: Sage.

Guerzoni, M. and Nuccio, M. (2013) 'Music Consumption at the Dawn of the Music Industry: The Rise of a Cultural Fad', Journal of Cultural Economics, 38(2), 145-171.

Gopinath, S. and Stanyek, J. (2013) The Oxford Handbook of Mobile Music Studies, Volume 1 and 2, Oxford: Oxford University Press.

Hellbrun, J. (1993) 'Innovation in Art, Innovation in Technology and the Future of the High Arts', Journal of Cultural Economics, 17(1), 89-98.

Howard, P.N. and Jones, S. (2005) Sociedad on-Line: Internet En Contexto, Barcelona: Editorial UOC.

Kusek, D. and Leonhard, G. (2005) The Future of Music: Manifesto for the Digital Music Revolution, Boston: Berklee Press.

Ministerio de Cultura División de Estadísticas Culturales (2011) Encuesta de Hábitos y Prácticas Culturales en España 2010-2011, Ministerio de Cultura. Secretaría General Técnica. Subdirección General de Publicaciones, Información y Documentación.

Miller, V. (2011) Understanding Digital Culture, Thousand Oaks: SAGE.

O'Hara, K. and Brown, B. (2006) Consuming Music Together: Social and Collaborative Aspects of Music Consumption Technologies, Dordrecht: Kluwer Academic Publishers.

Ordanini, A. and Parasuraman, A. (2012) 'A Conceptual Framework for Analyzing ValueCreating Service Ecosystems: An Application to the Recorded-Music Market', in S. Vargo and R. Lusch (eds), Special Issue - Toward a Better Understanding of the Role of Value in Markets and Marketing (Review of Marketing Research, Volume 9), Emerald Group Publishing Limited, pp.171 - 205.

Thompson, S. (2006) 'Audience Responses to a Live Orchestral Concert', Musicae Scientiae, 10(2), 215-244.

Vuust P. and Kringelbach, M. (2010) 'The Pleasure of Making Sense of Music', Interdisciplinary Science Reviews, 35, 166-82.

Anna Ibáñez Cantí completed a BA (Mus) degree in Classical Music Performance in 2004 and has been working as a pianist until 2014 in Spain, Holland, Thailand, Singapore and South Korea. Meanwhile, in 2007, she began to study Advertising and Public Relations, graduating in 2011 at the Open University of Catalonia (UOC). She kept on complementing her formation with several courses on marketing, persuasive communication and copy writing. In 2012 she undertook a master's research degree at the UOC: 'Information and Knowledge Society' in the area of sociology, where she wrote her master's thesis in 2014 entitled: 'Classical music as a cultural artefact in Spanish Society: an analytical study through the circuit of culture'. Her studies have been supported by the Ministry of Spain and the Agency for Management of University and Research 
Grants (AGAUR) from whom she got a scholarship to work as an Academic Assistant through an internship at the Open Univerity of Catalonia (UOC). Recently she has applied to pursue a PhD at the same University.

Email: aibanezmail@gmail.com 